\title{
Time for a new paradigm shift in myocardial infarction
}

\author{
Emre K. Aslanger (iD, H. Pendell Meyers' ${ }^{(1)}$, Stephen W. Smith² (i) \\ Department of Cardiology, Marmara University Pendik Training and Research Hospital; İstanbul-Turkey \\ ${ }^{1}$ Department of Emergency Medicine, Carolinas Medical Center, Charlotte; North Carolina-United States of America \\ ${ }^{2}$ Department of Emergency Medicine, University of Minnesota, Hennepin County Medical Center, Minneapolis; Minnesota-United States of America
}

\section{ABSTRACT}

The ST-elevation myocardial infarction (STEMI)/non-STEMI paradigm per the current guidelines has important limitations. It misses a substantial proportion of acute coronary occlusions (ACO) and results in a significant amount of unnecessary catheterization laboratory activations. It is not widely appreciated how poor is the evidence base for the STEMI criteria; the recommended STEMI cutoffs were not derived by comparing those with $\mathrm{ACO}$ with those without and not specifically designed for distinguishing patients who would benefit from emergency reperfusion. This review aimed to discuss the origins, evidence base, and limitations of STEMI/non-STEMI paradigm and to call for a new paradigm shift to the occlusion $\mathrm{MI}(\mathrm{OMI}) /$ non-OMI.

Key words: acute coronary syndrome, coronary artery disease, coronary occlusion, electrocardiogram, myocardial infarction

Cite this article as: Aslanger EK, Meyers PH, Smith SW. Time for a new paradigm shift in myocardial infarction. Anatol J Cardiol 2021; 25: 156-62.

\section{Introduction}

Surveying the history of myocardial infarction, the prereperfusion era is the dark ages for today's cardiologists. It may be easy to chuckle at the naivete of the management approach for patients with acute coronary occlusion (ACO) during that era (Fig. 1), and it may seem mysterious that the medical community reacted so slowly to the accumulating evidence (Fig. 2) (1-12). However, the physicians of the past were no less certain that they were providing the best possible treatment options available as are today's clinicians. Therefore, we must ask ourselves if we, too, are unaware of the obvious opportunities for improvement in the management of $\mathrm{ACO}$, and what steps we can take to enact those improvements.

As the historical timeline shows, it has been more than a century since acute myocardial infarction (AMI) was linked to coronary occlusion (1) and half a century since acute thrombosis was blamed as the primary mechanism (7). Since then, it has been of the utmost importance to distinguish patients with ACO or near occlusion, whose myocardium is at imminent risk of irreversible infarction without immediate reperfusion, from those patients with myocardium that is at risk, but not imminently and who can be stabilized with medical therapy. Before the reperfusion era, and even well into that era, the established AMI paradigm used for this differentiation was the 0 -wave/non-0-wave AMI dichotomy (9). As clinicians had little to offer patients for opening acutely occluded arteries, this paradigm was actually used to retrospectively classify patients according to whether their subsequent ECG developed 0 -waves, the ominous sign of the irreversible transmural loss of myocardium. However, the term "O-wave $\mathrm{MI}$ " implicitly referred to ACO that clinicians had not been able to intervene upon.

At the end of the last millennium, as a result of large-scale randomized-controlled trials (RCTs) comparing fibrinolytics with placebo, there was a revolutionary paradigm shift from 0-wave $\mathrm{MI} /$ non-Q-wave MI to STEMI/non-STEMI (NSTEMI). The seminal Fibrinolytic Therapy Trialists' (FTT) meta-analysis (10), which pooled data from 58,600 patients who were enrolled in all 9 RCTs

Address for Correspondence: Dr. Emre K. Aslanger, Marmara Üniversitesi Pendik Eğitim ve Araştırma Hastanesi,

Kardiyoloji Anabilim Dalı, İstanbul-Türkiye

Phone: +90 5325109796 E-mail: mr_aslanger@hotmail.com

Accepted Date: 08.01.2021 Available Online Date: 19.02.2021

(C) Copyright 2021 by Turkish Society of Cardiology - Available online at www.anatoljcardiol.com DOl:10.5152/AnatolJCardiol.2021.89304 


\section{HIGHLIGHTS}

- The STEMI/NSTEMI paradigm fails to diagnose nearly a quarter of acute coronary occlusions.

- ECG can detect acute coronary occlusion even when STEMI criteria are not fulfilled.

- We think that it is time to replace the STEMI/NSTEMI with a new $0 \mathrm{MI} / \mathrm{NOMI}$ paradigm.

- We believe this paradigm shift have the potential of improving the acute management of $\mathrm{MI}$.

\section{OUTLITE TOR MANAGRHEYT OF HEART DISEASS}

\section{CORONARY OCCLUSION}

11l sudden attacks of substernal pain or feelin 5 of compression which are persisted over a period of one hour should be considered coronar ooclualon and treated as such unt1l proven otherw1 se.

mergency Treatment:

1. Put the patient at ease -- that 18, make him as comfortable as possible. A minimal history and physical is indicated in the very acute case.

2. Absolute bed rest is essential.

8. Oxycen should be started Imrediately and continued unt1l the patient is out of danger.

4. Relleve pain by giving:

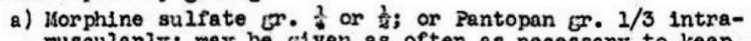
muscularly; may be given as of ten 8 s necessary to keep patient quiet. Atropine Gr. $1 / 150$ should be given at the same time.

b) Aminophyliin $\mathrm{gr}$. $7 \frac{\lambda}{2}$ intravenously in $20 \mathrm{cc}$. of wațer to be given slowly every 6 hours for 4 to 8 infections.

5. Apply external heat -- blankets, hot water bottle, etc.

6. Apply externa hat

intravenously, or Cafíe ine Sodium Benzoate ${ }^{2}$. $7 \hat{\mathrm{z}}$ if necessary.

7. Feed petient, restrict visitors, relieve distention, give no

enemas and only lifht food if tolerated.

Quinidine gr. 5 every six hours ma be of value if ectoplo

beats or arrhythries develop.

9. Avold adrenaline, nitrites and difitalls.

10. B.K.G. Imediateiy, along with $\mathrm{\nabla}$. B.C. and sedimentation rate.

lost Drergency ireatmont

1. Enforce complete bed rest for six weeks.

2. Xanthine derivatives are Indicated such as:

a) Glucophylin

b) Aminophyllin

3. Vasocilitation alded by N1cotinlc Acid 50 mom., t.1.d.

4. Light diet - low caloric.

Xeep stools loose by mineral oil daily or small enemas

as necessary.

Sedation; Plienobarbitol ar. $\frac{1}{8}$ q.1.d., or nore $1 f$ necessary

to keep patient quiet.

- Serial $B_{0} K_{0} G_{0}$ 'g aro inas catod.

Figure 1. An old outline for management of acute coronary occlusion (Cook County Hospital Intern Manual, Year Book Publishers, Chicago, US, 1955).

of thrombolytics versus placebo of at least 1,000 patients, showed an impressive $3 \%$ absolute reduction in short-term mortality. This was an unmatched breakthrough in the entire history of cardiology, but one critical question was obscured by the elation over that great success. Although patients with ACO were the ones who were most expected to benefit from emergent reperfusion, how did these studies attempt to identify those with ACO from those without? Surprisingly, they did not. Angiography was not employed in these studies, either prior to or after therapy. Instead of enrolling patients with proven ACO, the researchers randomized patients with "suspected AMI" to thrombolytics versus placebo. In general, these were high-risk patients with acute chest pain and with concerning but unde- fined electrocardiographic (ECG) findings. Overall, the group that received fibrinolytics had a significantly lower mortality. In a post-hoc analysis, the authors compared the effects of fibrinolytics in all patients to the effects in subsets of patients with ST-depression (STD), ST-elevation (STE), and "normal." Unfortunately, only 4 of the RCTs defined their version of STE, and these 4 had varying cutoffs and methods of measurement, usually not specified. Compared with giving fibrinolytics to all the patients regardless of ECG findings, using an undefined amount of STE as an arbiter of fibrinolytics administration produced an improvement in the number-needed-to-treat for short-term mortality from 56 to 43. Conversely, the subgroups of STD and "normal" ECG showed a non-significant trend to mortality harm. With these findings, the term STEMI became almost synonymous with ACO that necessitates acute reperfusion. Later, after finetuning of STE cutoffs by several investigators comparing the normal variant STE to STE in AMI (but, again, without the use of angiography) (13-16), "STEMI criteria" became a guideline-supported central dogma of cardiology (17-19).

At this point, we must ask ourselves the abovementioned foundational question: Are we perhaps unaware of errors in our current approach and thus ignoring opportunities for improvement in the management of ACO? Unfortunately, the answer seems to be yes.

\section{Caveats of the STEMI/NSTEMI paradigm}

The STEMI/NSTEMI paradigm is neither sensitive nor specific for the identification of ACO as it was flawed from the start. In the FTT meta-analysis (10), there were undoubtedly many patients with false positive STE (STE due to non-AMI conditions) who received thrombolytics, thus gaining no benefit despite the risk. Conversely, in the "normal" ECG and STD subgroups, there were doubtless many patients with ACO (including patients with "posterior" AMI, hyperacute T waves, and so on) whose benefit was confounded by those with a normal or STD ECG who did not have ACO (Fig. 3). Overall, without any ECG subgroup analysis, the group that received fibrinolytics had a lower mortality reflecting a high enough prevalence of $\mathrm{ACO}$ in the population with STE in whom benefit of administering fibrinolytics overweighs their harm.

As mentioned above, the STE cutoffs recommended in the $4^{\text {th }}$ universal definition of $\mathrm{Ml}$ (17) did not originate from these studies; instead, they were derived from studies comparing healthy individuals with those with AMI diagnosed by CK-MB, not by the presence of ACO (13-16). Thus, STEMI criteria were not originally derived or validated for the selection of patients with ACO who would most benefit from fibrinolytics or any other means of reperfusion intervention.

Because "STEMI" inappropriately became the term and concept used in place of ACO before ubiquitous cardiac catheterization was available, no study has ever questioned the benefit of emergent reperfusion therapies in ACO other than those manifesting the STEMI criteria. In the percutaneous coronary 


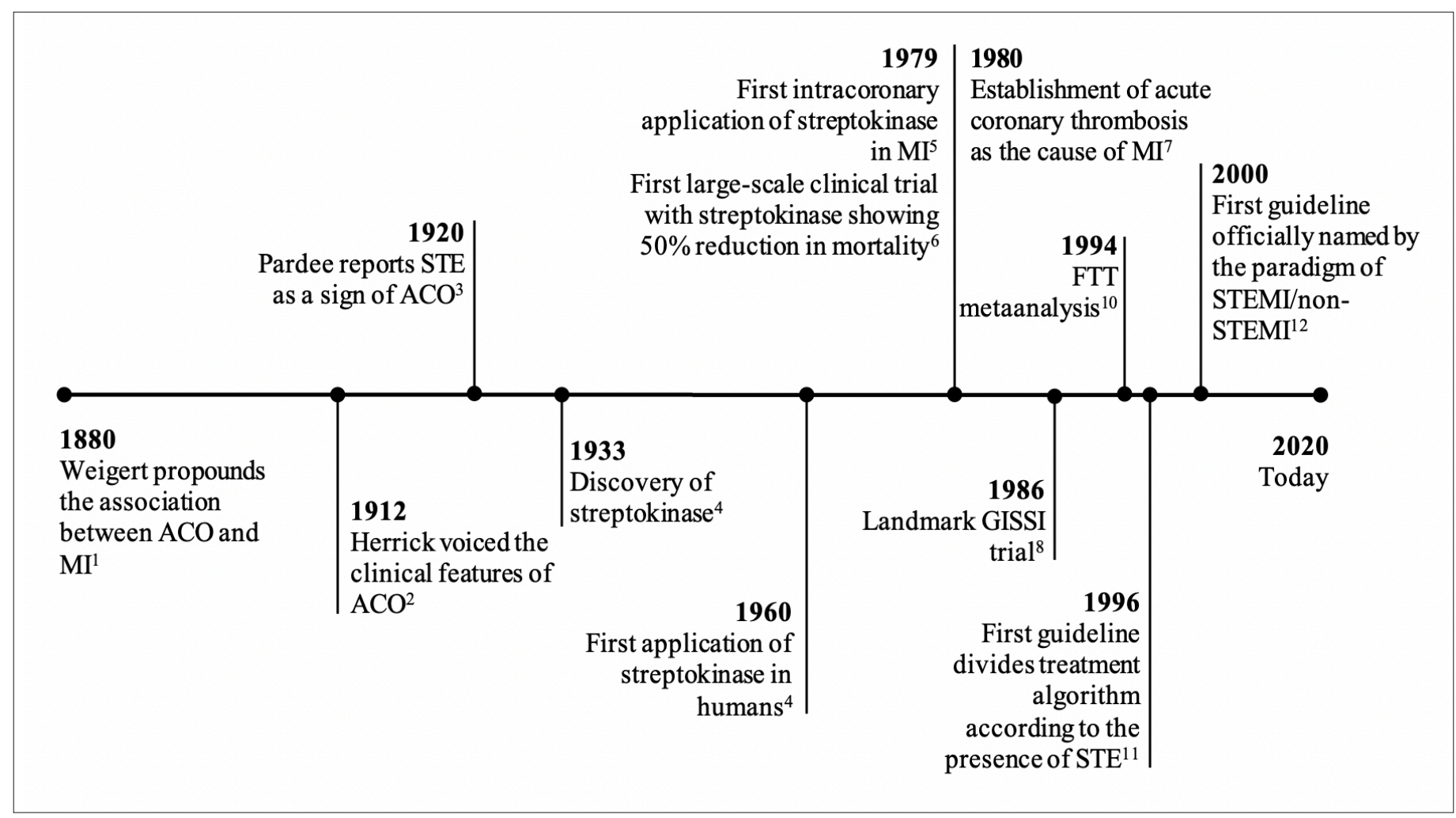

Figure 2. A timeline of major events providing insights into the acute myocardial infarction pathogenesis and management.

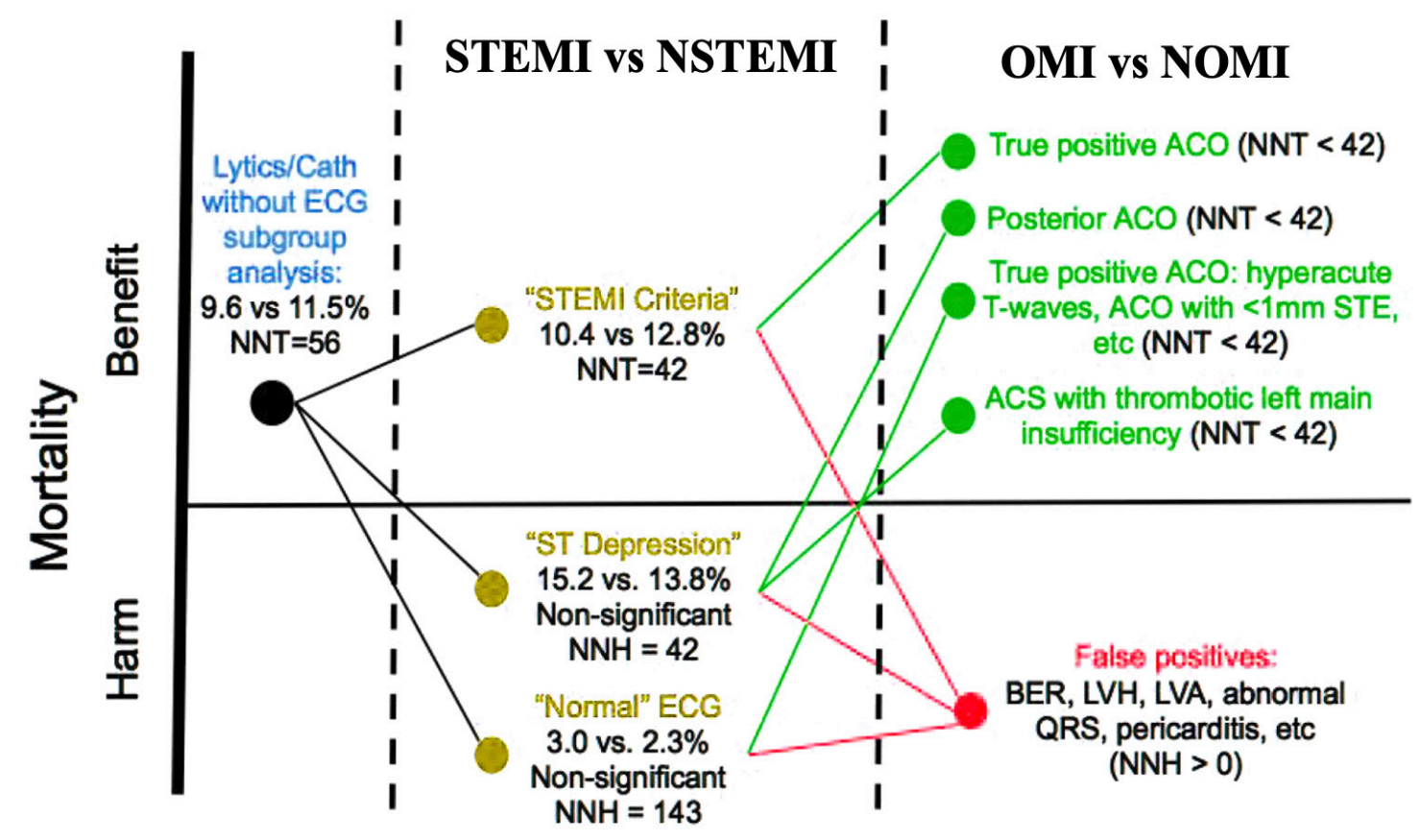

Figure 3. A comparison of ST-segment elevation myocardial infarction/ non-ST-segment elevation myocardial infarction and occlusion myocardial infarction/ non-occlusion myocardial infarction paradigms using the Fibrinolytic Therapy Trialists' meta-analysis mortality data. 
intervention era, STEMI criteria derived from studies of AMI as diagnosed by CK-MB are used, and their limited specificity for ACO cause a substantial amount of false catheterization laboratory activations (20-22). More importantly, the sensitivity is poor, missing at least one-third of the ACO (23-30) with the result that this unfortunate group of patients, labeled as NSTEMI, are deprived of emergent reperfusion therapy, just as they were in the old days of 0 -wave/non-0-wave $\mathrm{Ml}$ approach. Marti et al. (23) have shown that approximately one-fifth of the patients with ACO had $\geq 1 \mathrm{~mm}$ of STE, including $12.7 \%$ of left anterior descending artery occlusions. Schmitt et al. (24) have found that $29 \%$ of the patients with ACO did not meet STEMI criteria, with circumflex occlusions being the most missed (50\%). In the PARAGON-B trial (27) $27 \%$ of the patients with NSTEMI had completely occluded culprit vessels at the time of next day angiography. On average, these patients had a larger infarct size, worse left ventricular function, higher biomarkers, and higher long-term mortality than those of NSTEMI patients with open arteries. In a similar analysis of the TRITON-TIMI-38 (28), $26.2 \%$ of the patients with NSTEMI had completely occluded culprit vessels at the time of angiogram. A meta-analysis of 7 studies by Khan et al. (29) have showed that of the 40,777 NSTEMIs, $25.5 \%$ had ACO on angiography an average of 24 hours after presentation, and these patients with ACO but without STE had a 1.5 times higher relative risk of mortality compared with those without ACO. Of note, these numbers may underestimate ACO in NSTEMI as a large percentage of total thrombotic occlusions spontaneously reperfuse by the next-day angiogram; unfortunately, many only autolyse after a substantial loss of myocardium. Conversely, the occlusion might have also occurred later than the ECG decision point, but the recognition of this pathologic substrate that leads to ACO in the short term is still an important issue.

Some physicians who are unfamiliar with the source of the STEMI/NSTEMI paradigm might actually believe that patients with ACO but without STE on their ECG do not gain any benefit from reperfusion. Accordingly, many objections to the need for a paradigm change center around studies that purport to show that early angiography for patients with undifferentiated NSTEMI does not result in better outcomes (31-38). These objections fail to take into account that these studies excluded patients with persistent symptoms, and/or did not actually use very early intervention. In the largest such study, patients with persistent symptoms were excluded, and "early" angiography was at a mean of 16 hours; even so, patients with a GRACE score of $>140$ did indeed benefit from earlier intervention (31). In studies that did not exclude patients with persistent symptoms, and patients underwent truly early intervention, outcomes were indeed better (36-38). Even if all such trials were free of these methodological issues and had instead shown no benefit, they still would not be applicable to the question of whether the subset of NSTEMIs with ACO benefit from emergent reperfusion because these trials did not report the presence or absence of angiographic ACO, much less the outcomes in these patients.
These findings have 2 important messages with the same implication: We need to reshape our minds to understand that ACO needing reperfusion is clearly not synonymous with STEMI because NSTEMI with unrecognized ACO has higher short and long-term risk of mortality than NSTEMI with an open artery and similar to STEMI $(39,40)$. In addition, although the current guidelines recommend urgent ( $<2$ hours) invasive evaluation "regardless of ECG or biomarker findings" in patients with persistent pain, hemodynamic compromise, severe heart failure, and/or arrhythmias to identify patients with ACO but without STE (1719), these clinical parameters did not compensate for the silence of the ECG in the abovementioned studies. Furthermore, it is clear that there is a substantial deviation from the guidelines or there would not be so many occluded arteries in the 24-hour angiogram. It appears that even in the context of a highly observed setting of an RCT, physicians did not identify the patients with ACO among all the patients with undifferentiated chest pain.

\section{STEMI/NSTEMI paradigm focuses only on ST-segment}

The term "STEMI" is and has been a major obstacle to improvement. It cognitively inspires us to think that only the STsegment matters. It leads us to ignore other ECG variables, such as the preceding ORS-complex, the T-wave, or even the morphology of ST-segment itself. However, ACO can be reliably recognized with the help of many ECG findings other than the STE cutoffs recommended by the $4^{\text {th }}$ universal definition of MI, such as minor STE not fulfilling STEMI criteria (41), STE disproportionate to preceding ORS $(42,43)$, unusual patterns with contiguous leads showing opposite ST deviations $(44,45)$, and some patterns not showing STE at all $(46,47)$. The universal definition does in fact mention that there are other ECG findings of ACO than STE, which supports the argument that the name of ACO-MI should not be STEMI, but rather occlusion MI (OMI).

Furthermore, the differentiation of OMI from non-OMI (NOMI) and from non-cardiac chest pain does not end with the ECG. Not only may OMI have no STE, whatsoever; but OMI may also, in fact, present with a normal ECG (without even any subtle, nondiagnostic findings) and is sometimes only diagnosable by biomarkers, echocardiography $(48,49)$, or angiography, including CT angiography (50).

\section{STEMI/NSTEMI paradigm does not focus on pathology, instead focuses on the test}

The STEMI/NSTEMI paradigm uses a feature (STE) of a test (the ECG) as the name of an underlying pathology which is not accurately diagnosed by the test, which creates the "no false negative paradox." If there is no "diagnostic" STE, then there is no STEMI (even if there is ACO), and thus there can be no false negative test. Even in the presence of potentially fatal but reversible ACO, a negative test is a true negative for absence of STEMI! This has real consequences. When a patient is admitted with an NSTEMI and has an ACO on the next-day angiogram, 
that patient still gets a diagnosis of "NSTEMI," and the admitting physician does not get the feedback of "missed a STEMI" because, by definition, this was not a missed STEMI: the standard of care was followed. However, a great opportunity was missed to diagnose an ACO and save the patient's myocardium and possibly prevent heart failure and even death.

If we still use a surrogate sign paradigm (STEMI/NSTEMI) which does not accurately reflect the real underlying pathology (ACO), with the result that a large number of patients under our care helplessly infarct a large amount of myocardium, can we really boast that we have emerged from the dark ages? We should name the disease according to the pathologic substrate itself (ACO-MI, or OMI for short).

\section{STEMI/NSTEMI paradigm is not our best option}

Recently, Meyers et al. (51) performed a retrospective casecontrol study of 808 patients with suspected ACS symptoms and compared the accuracy of STEMI criteria with the structured expert ECG interpretation, which incorporates other findings of OMI, including hyperacute T waves, STD of posterior OMI, STE less than the STEMI criteria cutoffs, and so on. Both the interpreters had significantly higher sensitivity ( $86 \%$ versus $41 \%$ and $80 \%$ versus $36 \%$ ) for the detection of $0 \mathrm{MI}$ using the structured expert interpretation rather than using STEMI criteria, with similar specificity. Patients with STEMI (-) OMI had similar infarct size measured by peak troponin but greater delays to angiography compared with patients with STEMI (+) OMI. The interpreters had $94 \%$ agreement for the diagnosis of $\mathrm{OMI}$ and kappa value 0.849 . A total of $55 \%$ of $0 \mathrm{Mls}$ were correctly diagnosed a median of 1.5 hours earlier by structured expert ECG interpretation than by STEMI criteria.

Another study by Meyers et al. (40) compared the STEMI/ NSTEMI with the OMI/NOMI paradigms in 467 consecutive patients with high-risk acute coronary syndrome. Among the 108 patients with $0 \mathrm{MI}$, only $60 \%$ had any ECG meeting STEMI criteria. Patients with STEMI (-) OMI had similar peak troponins, wall motion abnormalities, and clinical outcomes as the patients with STEMI (+) OMI but were much less likely to receive emergent catheterization ( $28 \%$ versus $76 \%, \mathrm{p}<0.001)$. These data support the notion that patients with STEMI (-) OMI likely represent a missed opportunity under the STEMI/NSTEMI paradigm.

Similarly, the Dlagnostic accuracy of electrocardiogram for acute coronary OCCIUsion resuLTing in myocardial infarction (DIFOCCULT) study (39) compared the OMI/NOMI approach with the STEMI/NSTEMI paradigm. This was the largest study specifically designed to challenge 20 years of unquestioned dominance of the STEMI/NSTEMI paradigm. In this study, a set of predefined ECG findings in addition to STEMI criteria were used, and the final outcome was a composite ACO endpoint. In accordance with the previous observations, over one-fourth of the patients initially classified as having NSTEMI were re-classified by the ECG reviewers as having $\mathrm{OMI}$. This subgroup had a higher frequency of $\mathrm{ACO}$, myocardial damage, and both in-hospital and long-term mortality compared with those of the NOMI group. The OMI/NOMI approach to the ECG had a superior diagnostic accuracy compared with the STEMI/NSTEMI approach in the prediction of both ACO and long-term mortality. Furthermore, early intervention in patients with OMI-predicting ECGs was associated with lower long-term mortality, whereas early intervention increased longterm mortality in patients with NOMI-predicting ECGs.

\section{Conclusion}

The STEMI/NSTEMI paradigm shift was a major advancement when it was first proposed but is a major obstacle to advancement in the diagnosis and management of ACO. In recent years, there has been considerable incremental progress in the recognition of ACO by ECG findings other than STE, as well as by the use of other diagnostic tools, such as echocardiography $(48,49)$, CT angiography (50), and conventional angiography. Future studies are needed to better delineate how these modalities could be incorporated into fast diagnostic pathways in difficult cases. However, if we miss the opportunity to change our current paradigm before the next set of AMI guidelines is released, the failure to implement our current knowledge will cost many lives. Therefore, we call for a new AMI paradigm shift from STEMI/NSTEMI to OMI/NOMI.

Acknowledgment: The authors would like to thank Sam Ghali, MD for providing us with Figure 1.

Conflict of interest: None declared.

Peer-review: Externally peer-reviewed.

Author contributions: Concept - E.K.A., H.P.M., S.W.S.; Design E.K.A., H.P.M., S.W.S.; Supervision - E.K.A., H.P.M., S.W.S.; Fundings None; Materials - None; Data collection \&/or processing - E.K.A., H.P.M., S.W.S.; Analysis \&/or interpretation - E.K.A., H.P.M., S.W.S.; Literature search - E.K.A., H.P.M., S.W.S.; Writing - E.K.A., H.P.M., S.W.S.; Critical review - E.K.A., H.P.M., S.W.S.

\section{References}

1. Weigert C. Ueber die pathologiische Gerinnugs-Vorgange. Arch Path Anat (Virchow) 1880; 79: 87-123. [Crossref]

2. Herrick JB. Clinical features of sudden obstruction of the coronary arteries. JAMA 1912; 23: 2015-22. [Crossref]

3. Pardee HEB. An electrocardiographic sign of coronary artery obstruction. Arch Intern Med 1920; 26: 244-57.[Crossref]

4. Sherry S. Personal reflections on the development of thrombolytic therapy and its application to acute coronary thrombosis. Am Heart J 1981; 102: 1134-8. [Crossref]

5. Rentrop KP, Blanke H, Karsch KR, Wiegand V, Köstering H, Oster H, et al. Acute myocardial infarction: intracoronary application of nitroglycerin and streptokinase. Clin Cardiol 1979; 2: 354-63. [Crossref]

6. Streptokinase in acute myocardial infarction. European Cooperative Study Group for Streptokinase Treatment in Acute Myocardial Infarction. N Engl J Med 1979; 301: 797-802. [Crossref] 
7. DeWood MA, Spores J, Notske R, Mouser LT, Burroughs R, Golden MS, et al. Prevalence of total coronary occlusion during the early hours of transmural myocardial infarction. N Engl J Med 1980; 303: 897-902. [Crossref]

8. Effectiveness of intravenous thrombolytic treatment in acute myocardial infarction. Gruppo Italiano per lo Studio della Streptochinasi nell'Infarto Miocardico (GISSI). Lancet 1986; 1: 397-402.

9. Ryan TJ, Anderson JL, Antman EM, Braniff BA, Brooks NH, Califf $\mathrm{RM}$, et al. ACC/AHA guidelines for the management of patients with acute myocardial infarction. A report of the American College of Cardiology/American Heart Association Task Force on Practice Guidelines (Committee on Management of Acute Myocardial Infarction). J Am Coll Cardiol 1996; 28: 1328-428.

10. Indications for fibrinolytic therapy in suspected acute myocardial infarction: collaborative overview of early mortality and major morbidity results from all randomised trials of more than 1000 patients. Fibrinolytic Therapy Trialists' (FTT) Collaborative Group. Lancet 1994; 343: 311-22. [Crossref]

11. Ryan TJ, Antman EM, Brooks NH, Califf RM, Hillis LD, Hiratzka LF, et al. 1999 update: ACC/AHA guidelines for the management of patients with acute myocardial infarction. A report of the American College of Cardiology/American Heart Association Task Force on Practice Guidelines (Committee on Management of Acute Myocardial Infarction). J Am Coll Cardiol 1999; 34: 890-911. [Crossref]

12. Braunwald E, Antman EM, Beasley JW, Califf RM, Cheitlin MD, Hochman JS, et al. ACC/AHA guidelines for the management of patients with unstable angina and non-ST-segment elevation myocardial infarction: executive summary and recommendations. A report of the American College of Cardiology/American Heart Association task force on practice guidelines (committee on the management of patients with unstable angina). Circulation 2000; 102: 1193-209. [Crossref]

13. Menown IB, Mackenzie G, Adgey AA. Optimizing the initial 12-lead electrocardiographic diagnosis of acute myocardial infarction. Eur Heart J 2000; 21: 275-83. [Crossref]

14. Macfarlane PW. Age, sex, and the ST amplitude in health and disease. J Electrocardiol 2001; 34 Suppl: 235-41. [Crossref]

15. Wu J, Kors JA, Rijnbeek PR, van Herpen G, Lu Z, Xu C. Normal limits of the electrocardiogram in Chinese subjects. Int $\mathrm{J}$ Cardiol 2003; 87: 37-51. [Crossref]

16. Macfarlane PW, Browne D, Devine B, Clark E, Miller E, Seyal J, et al. Modification of ACC/ESC criteria for acute myocardial infarction. J Electrocardiol 2004; 37 Suppl: 98-103. [Crossref]

17. Thygesen K, Alpert JS, Jaffe AS, Chaitman BR, Bax JJ, Morrow DA, et al.; Executive Group on behalf of the Joint European Society of Cardiology (ESC)/American College of Cardiology (ACC)/American Heart Association (AHA)/World Heart Federation (WHF) Task Force for the Universal Definition of Myocardial Infarction. Fourth Universal Definition of Myocardial Infarction (2018). J Am Coll Cardiol 2018; 72: 2231-64. [Crossref]

18. O'Gara PT, Kushner FG, Ascheim DD, Casey DE Jr, Chung MK, de Lemos JA, et al.; American College of Cardiology Foundation/ American Heart Association Task Force on Practice Guidelines. 2013 ACCF/AHA guideline for the management of ST-elevation myocardial infarction: a report of the American College of Cardiology Foundation/American Heart Association Task Force on Practice Guidelines. Circulation 2013; 127: e362-425.

19. Ibanez B, James S, Agewall S, Antunes MJ, Bucciarelli-Ducci C, Bueno H, et al.; ESC Scientific Document Group. 2017 ESC
Guidelines for the management of acute myocardial infarction in patients presenting with ST-segment elevation: The Task Force for the management of acute myocardial infarction in patients presenting with ST-segment elevation of the European Society of Cardiology (ESC). Eur Heart J 2018; 39: 119-77. [Crossref]

20. McCabe JM, Armstrong EJ, Kulkarni A, Hoffmayer KS, Bhave PD, Garg S, et al. Prevalence and factors associated with false-positive ST-segment elevation myocardial infarction diagnoses at primary percutaneous coronary intervention-capable centers: a report from the Activate-SF registry. Arch Intern Med 2012; 172: 864-71. [Crossref]

21. Larson DM, Menssen KM, Sharkey SW, Duval S, Schwartz RS, Harris J, et al. "False-positive" cardiac catheterization laboratory activation among patients with suspected ST-segment elevation myocardial infarction. JAMA 2007; 298: 2754-60. [Crossref]

22. Kontos MC, Kurz MC, Roberts CS, Joyner SE, Kreisa L, Ornato JP, et al. An evaluation of the accuracy of emergency physician activation of the cardiac catheterization laboratory for patients with suspected ST-segment elevation myocardial infarction. Ann Emerg Med 2010; 55: 423-30. [Crossref]

23. Martí D, Mestre JL, Salido L, Esteban MJ, Casas E, Pey J, et al. Incidence, angiographic features and outcomes of patients presenting with subtle ST-elevation myocardial infarction. Am Heart J 2014; 168: 884-90. [Crossref]

24. Schmitt C, Lehmann G, Schmieder S, Karch M, Neumann FJ, Schömig A. Diagnosis of acute myocardial infarction in angiographically documented occluded infarct vessel: limitations of ST-segment elevation in standard and extended ECG leads. Chest 2001; 120: 1540-6. [Crossref]

25. Koyama Y, Hansen PS, Hanratty CG, Nelson GI, Rasmussen HH. Prevalence of coronary occlusion and outcome of an immediate invasive strategy in suspected acute myocardial infarction with and without ST-segment elevation. Am J Cardiol 2002; 90: 579-84. [Crossref]

26. Abbas AE, Boura JA, Brewington SD, Dixon SR, O'Neill WW, Grines $\mathrm{CL}$. Acute angiographic analysis of non-ST-segment elevation acute myocardial infarction. Am J Cardiol 2004; 94: 907-9. [Crossref]

27. Wang TY, Zhang M, Fu Y, Armstrong PW, Newby LK, Gibson CM, et al. Incidence, distribution, and prognostic impact of occluded culprit arteries among patients with non-ST-elevation acute coronary syndromes undergoing diagnostic angiography. Am Heart J 2009; 157: 716-23. [Crossref]

28. Pride YB, Tung P, Mohanavelu S, Zorkun C, Wiviott SD, Antman EM, et al.; TIMI Study Group. Angiographic and clinical outcomes among patients with acute coronary syndromes presenting with isolated anterior ST-segment depression: a TRITON-TIMI 38 (Trial to Assess Improvement in Therapeutic Outcomes by Optimizing Platelet Inhibition With Prasugrel-Thrombolysis In Myocardial Infarction 38) substudy. JACC Cardiovasc Interv 2010; 3: 806-11. [Crossref]

29. Khan AR, Golwala H, Tripathi A, Bin Abdulhak AA, Bavishi C, Riaz $\mathrm{H}$, et al. Impact of total occlusion of culprit artery in acute non-ST elevation myocardial infarction: a systematic review and metaanalysis. Eur Heart J 2017; 38: 3082-9. [Crossref]

30. Hillinger P, Strebel I, Abächerli R, Twerenbold R, Wildi K, Bernhard $D$, et al.; APACE Investigators. Prospective validation of current quantitative electrocardiographic criteria for ST-elevation myocardial infarction. Int J Cardiol 2019; 292: 1-12. [Crossref] 
31. Mehta SR, Granger CB, Boden WE, Steg PG, Bassand JP, Faxon DP, et al.; TIMACS Investigators. Early versus delayed invasive intervention in acute coronary syndromes. N Engl J Med 2009; 360: 2165-75. [Crossref]

32. Hoedemaker NPG, Damman P, Woudstra P, Hirsch A, Windhausen F, Tijssen JGP, et al.; ICTUS Investigators. Early Invasive Versus Selective Strategy for Non-ST-Segment Elevation Acute Coronary Syndrome: The ICTUS Trial. J Am Coll Cardiol 2017; 69: 1883-93. [Crossref]

33. van 't Hof AW, de Vries ST, Dambrink JH, Miedema K, Suryapranata $\mathrm{H}$, Hoorntje JC, et al. A comparison of two invasive strategies in patients with non-ST elevation acute coronary syndromes: results of the Early or Late Intervention in unStable Angina (ELISA) pilot study. $2 \mathrm{~b} / 3 \mathrm{a}$ upstream therapy and acute coronary syndromes. Eur Heart J 2003; 24: 1401-5. [Crossref]

34. Thiele H, Rach J, Klein N, Pfeiffer D, Hartmann A, Hambrecht R, et al.; LIPSIA-NSTEMI Trial Group. Optimal timing of invasive angiography in stable non-ST-elevation myocardial infarction: the Leipzig Immediate versus early and late PercutaneouS coronary Intervention triAl in NSTEMI (LIPSIA-NSTEMI Trial). Eur Heart J 2012; 33: 2035-43. [Crossref]

35. Montalescot G, Cayla G, Collet JP, Elhadad S, Beygui F, Le Breton H, et al.; ABOARD Investigators. Immediate vs delayed intervention for acute coronary syndromes: a randomized clinical trial. JAMA 2009; 302: 947-54. [Crossref]

36. Milosevic A, Vasiljevic-Pokrajcic Z, Milasinovic D, Marinkovic J, Vukcevic V, Stefanovic B, et al. Immediate Versus Delayed Invasive Intervention for Non-STEMI Patients: The RIDDLE-NSTEMI Study. JACC Cardiovasc Interv 2016; 9: 541-9. [Crossref]

37. Neumann FJ, Kastrati A, Pogatsa-Murray G, Mehilli J, Bollwein H, Bestehorn HP, et al. Evaluation of prolonged antithrombotic pretreatment ("cooling-off" strategy) before intervention in patients with unstable coronary syndromes: a randomized controlled trial. JAMA 2003; 290: 1593-9. [Crossref]

38. Reuter PG, Rouchy C, Cattan S, Benamer H, Jullien T, Beruben A, et al. Early invasive strategy in high-risk acute coronary syndrome without ST-segment elevation. The Sisca randomized trial. Int J Cardiol 2015; 182: 414-8. [Crossref]

39. Aslanger EK, Yıldırımtürk Ö, Şimşek B, Bozbeyoğlu E, Şimşek MA, Yücel Karabay $C$, et al. Dlagnostic accuracy of electrocardiogram for acute coronary OCCIUsion resuLTing in myocardial infarction (DIFOCCULT Study). Int J Cardiol Heart Vasc 2020; 30: 100603. [Crossref]

40. Meyers HP, Bracey A, Lee D, Lichtenheld A, Li WJ, Singer DD, et al. Comparison of the ST-Elevation Myocardial Infarction (STEMI) vs. NSTEMI and Occlusion MI (OMI) vs. NOMI Paradigms of Acute MI. J Emerg Med 2020: S0736-4679(20)31070-2. [Crossref]
41. Miranda DF, Lobo AS, Walsh B, Sandoval Y, Smith SW. New Insights Into the Use of the 12-Lead Electrocardiogram for Diagnosing Acute Myocardial Infarction in the Emergency Department. Can J Cardiol 2018; 34: 132-45. [Crossref]

42. Smith SW, Khalil A, Henry TD, Rosas M, Chang RJ, Heller K, et al. Electrocardiographic differentiation of early repolarization from subtle anterior ST-segment elevation myocardial infarction. Ann Emerg Med 2012; 60: 45-56. [Crossref]

43. Aslanger $E$, Yıldırımtürk Ö, Bozbeyoğlu $E$, Şimşek B, Karabay $C Y$, Türer Cabbar A, et al. A Simplified Formula Discriminating Subtle Anterior Wall Myocardial Infarction from Normal Variant ST-Segment Elevation. Am J Cardiol 2018; 122: 1303-9. [Crossref]

44. Durant $E$, Singh A. Acute first diagonal artery occlusion: a characteristic pattern of ST elevation in noncontiguous leads. Am J Emerg Med 2015; 33: 1326.e3-5. [Crossref]

45. Aslanger E, Yıldırımtürk Ö, Şimşek B, Sungur A, Türer Cabbar A, Bozbeyoğlu $E$, et al. A new electrocardiographic pattern indicating inferior myocardial infarction. J Electrocardiol 2020; 61: 41-6. [Crossref]

46. Verouden NJ, Koch KT, Peters RJ, Henriques JP, Baan J, van der Schaaf RJ, et al. Persistent precordial "hyperacute" T-waves signify proximal left anterior descending artery occlusion. Heart 2009; 95: 1701-6. [Crossref]

47. Fox KA, Dabbous OH, Goldberg RJ, Pieper KS, Eagle KA, Van de Werf $F$, et al. Prediction of risk of death and myocardial infarction in the six months after presentation with acute coronary syndrome: prospective multinational observational study (GRACE). BMJ 2006; 333: 1091. [Crossref]

48. Eek C, Grenne B, Brunvand H, Aakhus S, Endresen K, Smiseth OA, et al. Strain echocardiography predicts acute coronary occlusion in patients with non-ST-segment elevation acute coronary syndrome. Eur J Echocardiogr 2010; 11: 501-8. [Crossref]

49. Rowland-Fisher A, Smith S, Laudenbach A, Reardon R. Diagnosis of acute coronary occlusion in patients with non-STEMI by pointof-care echocardiography with speckle tracking. Am J Emerg Med 2016; 34: 1914.e3-6. [Crossref]

50. Linde JJ, Kelbæk H, Hansen TF, Sigvardsen PE, Torp-Pedersen C, Bech J, et al. Coronary CT Angiography in Patients With Non-STSegment Elevation Acute Coronary Syndrome. J Am Coll Cardiol 2020; 75: 453-63. [Crossref]

51. Meyers HP, Bracey A, Lee D, Lichtenheld A, Li W, Singer D, et al. Abstract 12682: Accuracy of Expert Electrocardiography versus ST-Segment Elevation Myocardial Infarction Criteria for Diagnosis of Acute Coronary Occlusion Myocardial Infarction. Circulation 2020; 142: A12682. 